Article

\title{
Evaluation Method of Relative Humidity Changes in Below-Grade Concrete Structure Space Depending on Different Waterproofing Material and Installation Method
}

\author{
Ki-won An ${ }^{1}$, Kyu-hwan $\mathrm{Oh}^{2}{ }^{2}$ Bo Jiang ${ }^{3}$, Xingyang $\mathrm{He}^{3}$ and Sang-keun $\mathrm{Oh}^{3,4, *(\mathbb{D})}$ \\ 1 Department of Architecture, Graduate School, Seoul National University of Science \& Technology, 232 \\ Gongneung-ro, Nowon-gu, Seoul 01811, Korea; ankiwon@seoultech.ac.kr \\ 2 Department of Railway Construction Engineering, Graduate School of Railway, Seoul National University of \\ Science \& Technology, 232 Gongneung-ro, Nowon-gu, Seoul 01811, Korea; kyuhwan.oh@seoultech.ac.kr \\ 3 School of Civil Engineering, Architecture and Environment, Hubei University of Technology, Wuhan 430064, \\ China; jiangbo15@126.com (B.J.); hxycn@126.com (X.H.) \\ 4 School of Architecture, Seoul National University of Science \& Technology, 232 Gongneung-ro, Nowon-gu, \\ Seoul 01811, Korea \\ * Correspondence: ohsang@seoultech.ac.kr; Tel.: +82-2-970-6559
}

Received: 2 January 2020; Accepted: 3 February 2020; Published: 6 February 2020

\begin{abstract}
An evaluation method for assessing the difference in the relative humidity (RH) control performance of waterproofing material is proposed. For a demonstration of this evaluation method, two waterproofing materials (urethane coating and cementitious waterproofing material) installed with different methods (positive and negative side of concrete structure respectively) are exposed to temperature conditions representing three seasonal conditions: Summer $\left(40^{\circ} \mathrm{C}\right)$, spring/autumn $\left(20^{\circ} \mathrm{C}\right)$ and winter $\left(4^{\circ} \mathrm{C}\right)$. Condensation level changes on the inner side of the waterproofing material installed specimen is measured, and for derive criteria for comparison, three parameters based on the average $\mathrm{RH}$, intercept $\mathrm{RH}$ (derived from a linear regression analysis of $\mathrm{RH}$ measurement), and maximum relative humidity are derived for each different waterproofing material installed specimen. Based on quality specification for underground concrete structures, the demonstration evaluation establishes provisional standard criteria of below $70 \% \mathrm{RH}$, and all three parameters are evaluated to determine whether the tested waterproofing material/method complies to the performance requirement. Additional analysis through linear regression and cumulative probability density graphs are derived to evaluate the RH consistency and range parameters. The evaluation regime demonstrates a quantitative $\mathrm{RH}$ analysis method and apparatus, and a newly designed evaluation criteria is used to compare the RH control performance of positive-side installed urethane waterproofing materials and negative-side installed cementitious waterproofing material.
\end{abstract}

Keywords: relative humidity; positive-side waterproofing; negative-side waterproofing; below-grade concrete structure space; waterproofing material evaluation

\section{Introduction}

Many parts of East Asian and South East Asian countries are using below-grade spaces in urban locations for residential apartment building parking lot construction. This heightens social awareness that quality requirements of below-grade construction should be properly analyzed and identified. One of these requirements is humidity control. Generally, relative humidity (RH) control is achieved by installing electrical facilities such as air-conditioners, humidifiers, exhaust fans, and drainage. 
However, the United States Environmental Protection Agency, in their Moisture Control Guidance for Building Design, Construction and Maintenance outlines humidity control as a requirement for proper waterproofing as well. It is already a well-established fact that if the below-grade space is completely sealed from contact with ground water, it significantly enhances the moisture control of structure indoors [1]. However, there are few existing studies which discuss methods for selecting waterproofing materials that are best suited for this purpose. Existing specifications or test methods only focus on the physical properties of waterproofing membranes for selection criteria, and RH control performance is absent as a required property in almost all cases. Chang et al., in a study on the effect of exterior wall (positive-side installed) waterproofing membranes on humidity-temperature of below-grade concrete structure indicates that there are few studies that examine the correlation between $\mathrm{RH}$ conditions (condensation) and waterproofing [2].

Waterproofing with humidity control performance can potentially reduce the energy required to maintain optimal moisture and $\mathrm{RH}$ indoors without complete reliance on moisture control facilities, which in turn lowers annual electrical and maintenance costs. In this paper, a newly designed evaluation method based on RH change measurement of a simulated concrete structure interior specimens installed with different types of waterproofing method is proposed. By measuring the condensation changes of the interior of the specimen installed with positive and negative side waterproofing under a predetermined ambient condition results can be derived that will provide a difference between the two waterproofing material and methods. The following sections provide the literature review on the degradation mechanisms associated with leakage and $\mathrm{RH}$ in underground spaces and discussion on the requirement for a RH control performance evaluation method for waterproofing materials and methods.

\subsection{Structural Degradation Problems Due to Increase in RH in Concrete Structures}

Soils have characteristic capillary action, and water vapor migrates through the minute sized pathing in the soil and come in contact with the concrete structure from all direction [3]. Through the capillary action, water that penetrates the pores of the concrete layer condense into droplets once it reaches the interior due the difference in the ambient conditions. This formation of water in the interior of the structure can be a cause of number of sources for degradation, including delamination, mildew, staining and spalling [4]. This paper discusses two forms of moisture related structural degradation; (1) freeze-thawing and reinforcing steel corrosion, (2) spalling in cases of fire due to increased pressure from trapped moisture. Refer to Figure 1 for an illustration of the water ingress process in below grade concrete structures.

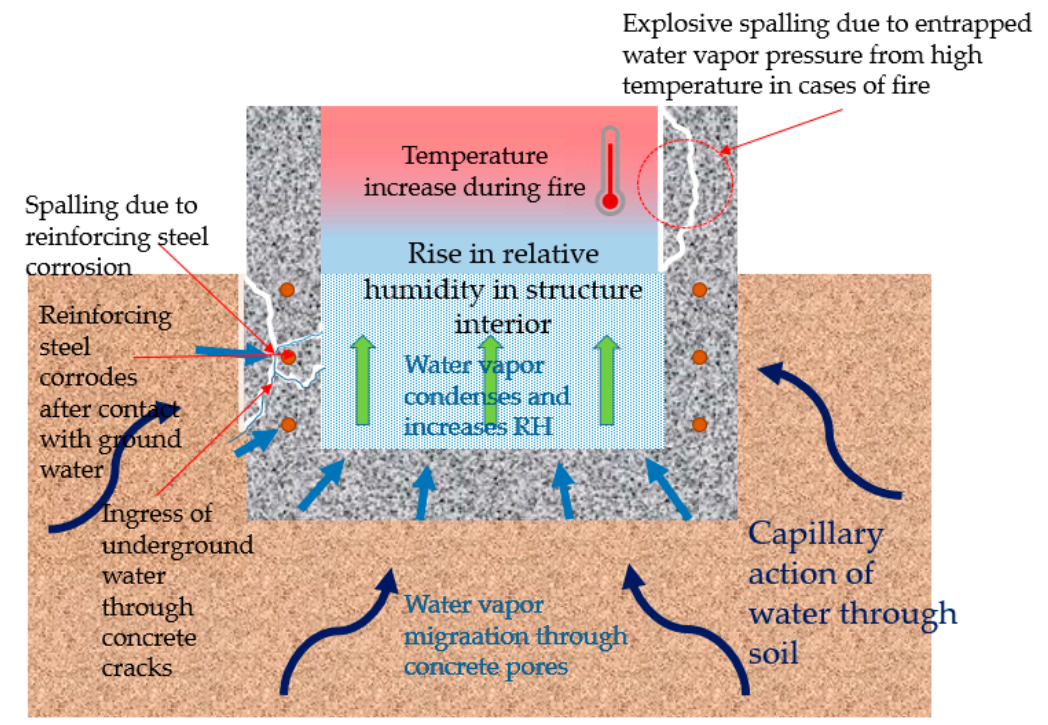

Figure 1. Condensation due to water vapor and water leakage ingress in below-grade concrete structures. 


\subsubsection{Reinforcing Steel Corrosion and Freeze Thaw}

In terms of structural durability, saturated concrete substrates are subject to more extreme degrees of freeze-thaw effect due to seasonal cycling, and can result in corrosion of reinforcing steel. Zhu et al. studies the behavior of steel corrosion under freeze-thawing environment and the study results show that freeze-thaw damage aggravates the steel corrosion in concrete. Their studies also reveal that concrete with waterproofing properties are more resistant to corrosion under freeze-thaw conditioning [5]. These factors indicate that humidity and moisture control in the concrete structure is required. Unless the structure undergoes proper maintenance, the feedback cycle of moisture related degradation in concrete structures creates more entry of moisture and RH in the structure interior [6]. $\mathrm{RH}$ and condensation are also a cause for corrosion. According to RA Francis and various sources, the minimum RH humidity below which reinforcing steel corrosion in concrete does not occur is around $80 \%$ [7].

\subsubsection{Spalling due to Pressurized Moisture in Concrete Due to Increase of Temperature (Fire Hazard)}

When concrete is exposed extreme high temperature (most common case being fire hazard), explosive spalling can potentially occur [8-10]. When residual moisture components in concrete after hydration reaction is heated, the pressure can eventually cause explosive spalling. Robert Jansson refutes this theory that the presence of moisture is a factor for reducing concrete strength which causes the spalling, rather than the increasing steam pressure [11]. According to his findings, presence of moisture in concrete can be a factor that reduces the strength in areas where spalling can occur in the form of surface flaking during fire exposure [11]. In his paper, experimental study on moisture in fire exposed concrete shows the development of a saturated moisture layer in concrete samples seen to spall during large scale fire exposure tests [11]. From the explicated mechanisms, it is evident that concrete exposed to constant moisture, due to either leakage or high $\mathrm{RH}$ become susceptible to spalling during fire hazard. To prevent this risk, the importance of optimal waterproofing and RH control performance can be stressed.

\subsection{Mold Growth, Discomfort, and Radon Due to Increase in RH}

Increase of RH and condensation in underground concrete structure space can create number of social issues. These social issues in the present literature is reviewed in the sections below to illustrate the importance of RH control in concrete structures. Three factors are discussed related discomfort, mold growth, and radon exposure.

\subsubsection{Mold Growth Due to Increase of RH}

Particularly in the case of U.S. and other humid climate regions such as Malaysia and Singapore, it is commonly documented that mold growth in basement can bring significant health risks to residents and in the indoors can produce volatile, bad smelling compounds. The JKR Guidelines on Preventions of Mold Growth in Buildings indicate that when the temperature, nutrient sources, spores, oxygen, and high RH conditions meet a certain level, this leads to mold growth in enclosed spaces [12]. Refer to Figure 2 for details.

Increase of RH in underground concrete structure spaces is mostly attributed to water leakage and poor insulation control. The JKR Guideline outlines the approximate expected RH humidity level for promoting mold growth to be above $70 \%$ in conjunction with other biological and ambient factors, and provides a control method ranging from proposed structural designs to architectural considerations [12]. Zuzana et al. provides a report on the varying ranges of moisture level conditions that allow mold growth, but roughly conclude that the critical level lie between the RH of $75 \%$ to 95\% [13]. Daranee et al. confirm that as hot and humid climate result in a higher risk for mold growth in the indoors of concrete structures [14], RH control should be maintained throughout the year. 


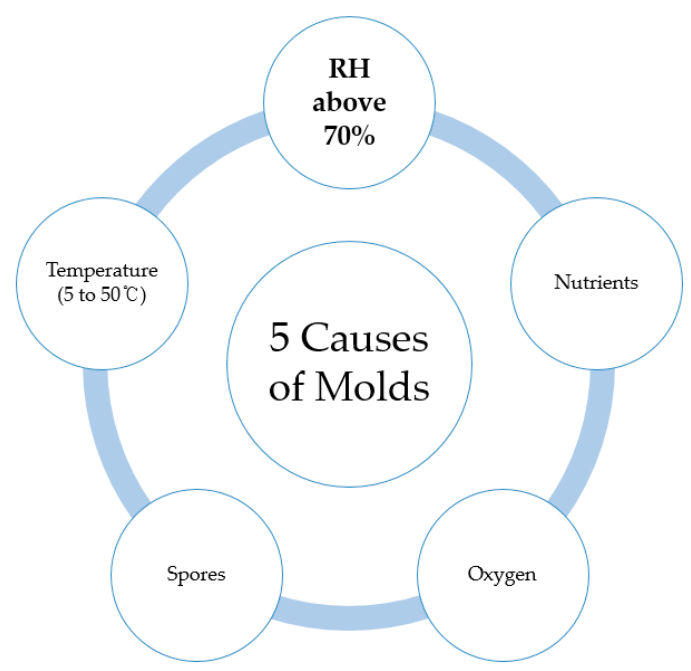

Figure 2. JKR Guidelines on Prevention of Mold Growth in Buildings [6].

In this regard, Johansson et al.'s studies indicate that leakage is identified as a cause for unnecessary increase in $\mathrm{RH}$, but details in the instruction for the selection of material and method is lacking [15]. While there are methods for mold growth prevention, Johansson's research provides conclusions in that standardized RH control evaluation method is currently lacking in this field.

\subsubsection{Discomfort Due to Increase of RH}

According to the American Society of Heating, Refrigerating and Air-Conditioning Engineers (ASHRAE), permissible operative temperature range by linear interpolation is between the limits of 0.5 and 1.0 clo. According to the Graphic Comfort Zone Method for Typical Indoor Environments [16]. The basis of the calculation is derived from the predicted mean vote (PMV) that uses heat balance principles to relate six key factors, which include air temperature, radiant temperature, applicable metabolic rate of the residents, clothing insulation, air speed, and humidity. The selected waterproofing method should ensure that the interior humidity and temperature conditions can meet the conditions outlined in the comfort index of ASHRAE, or other comfort zone method systems used as international standards.

Optimal/comfort humidity zone is always relative to the ambient conditions, and it is crucial to be able to examine the humidity control performance in below-grade concrete structures. There are existing sources that provide a reference or guideline on a humidex range and/or criteria, all of which can provide insight on the degree of impact RH have on the quality of concrete structure indoors [16]. However, studies do not commonly mention waterproofing method as a means of controlling RH to maintain the comfort humidity zone. The Environmental Protection Agency guideline Moisture Control Guidance for Building Design, Construction and Maintenance includes a brief clause on the importance of waterproofing for moisture control of buildings, but detailed specifications on waterproofing methodology is again absent in the guidelines [17].

\subsubsection{Health Related Issues Due to RH}

Water leakage induced increase of humidity in the interior of buildings can also bring risks of radon ingress. Although radon is normally harmless to the human body when taken in small quantities, enclosed spaces in below-grade structures or basement can result in the radon gas building up. Radon gas is a product of the radioactive decay of radium in natural minerals present in the underground soil, such granite, limestone, and other quarry rocks. The coarse gravel usually laid out before backfilling can also contain uranium that decay into radon particles.

Radon primarily enters the interior of structures due to air. Scholars such as C.J Groves-Kirkby et al. refute a direct correlation between RH and radon level [18], and active soil depressurization is 
normally applied to reduce both radon and soil moisture in infiltration [19]. However, high RH caused by the condensation effect due to direct leakage of water can provide indirect entry methods for the radon to enter the concrete interior. According to A. Fernandez-Cortes, the gaseous exchange between surface/underground and atmosphere is linked to the presence of pores and subsurface cavities, which act as storage or temporary sources of radon, and high degrees of moisture in the pores can dissolve the radon gas and enter the atmosphere through diffusion or advective transport [20]. Bradley Turk also provides a detailed study on the effect of RH on the ingress of radon into the interior of concrete structures [21]. Refer to Figure 3 for an illustration on the common way in which radon enters concrete structure interior.

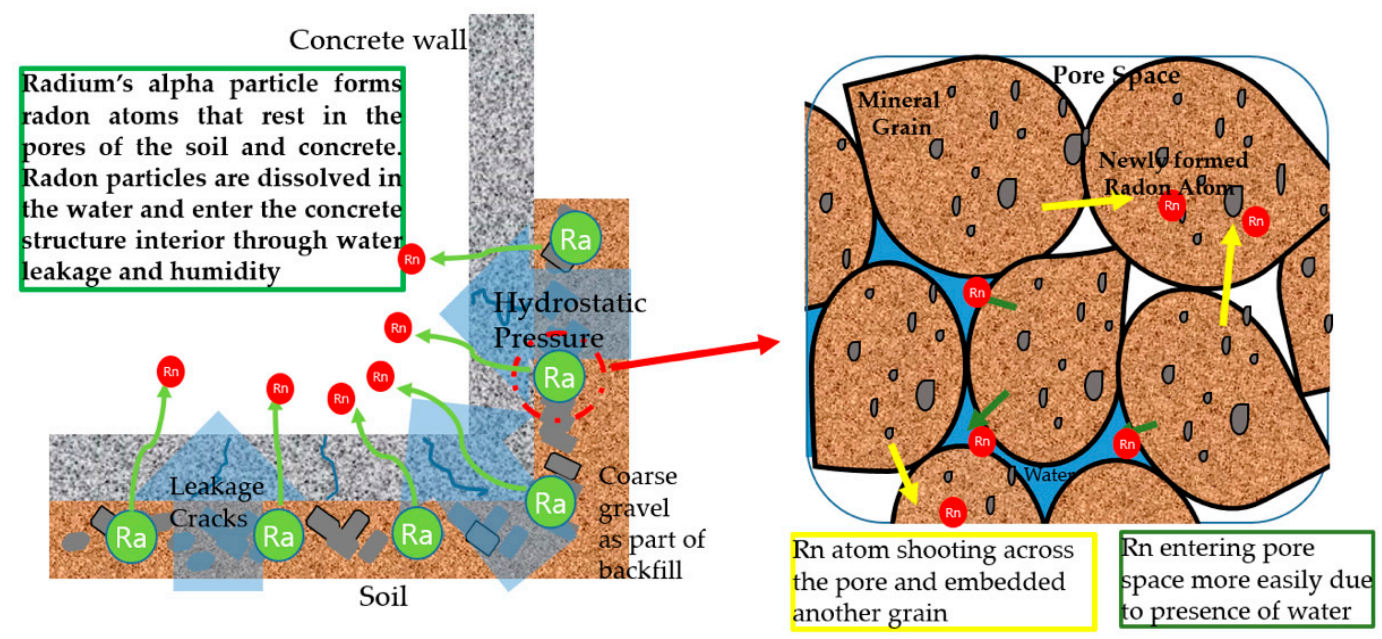

Figure 3. Radon ingress mechanism in below-grade concrete structures.

\section{Protection and Evaluation Methods}

While condensation and moisture related problems have long been known to be a cause for degradation of concrete structures and induce the correlated problems as outlined in the above, this factor has not been considered in many of studies related to waterproofing methods and material performance evaluation. National standards such as British Standard (BS EN 8102) [22], American Society for Testing and Materials (ASTM D7832) [23], or China's national standard (GB 50108) [24] on underground structure waterproofing guidelines all mention the importance of moisture control, but a method for comparatively evaluating different waterproofing materials and methods is not provided. In this regard, the following sections provide a review on the existing waterproofing materials and methods conventionally used in underground structures, and the respective characteristics are outlined to discuss the possibilities for a comparative evaluation on $\mathrm{RH}$ control performance. To illustrate the example of this situation, refer to the below Table 1 for details of the ASTM D 7832 for common performance attributes of waterproofing membrane applied to below-grade walls.

In order to achieve a quality waterproofing protection, this study proposes that humidity measurement changes in a below-grade structure simulated environment should be considered as a required performance attribute. In consideration of the above outlined potential problem mechanisms related to different types of waterproofing installation methods, systematic evaluation criteria, and test method for the selection of waterproofing method and material in new underground concrete structures should be proposed. 
Table 1. American Society for Testing and Materials (ASTM D7832) Waterproofing Material Physical Properties [23].

\begin{tabular}{|c|c|c|}
\hline Property & Standard & Criteria \\
\hline \multicolumn{3}{|c|}{ Waterproofing Material Physical Properties for Bituminous and non-bituminous organic } \\
\hline Resistance to Hydrostatic Pressure & Test Method D5385 & $\begin{array}{c}\text { No leaks at } 103 \mathrm{kPa}[15 \mathrm{psi}][34.65 \mathrm{ft} \text { head }] \text { or at } \\
\text { the maximum hydrostatic pressure determined } \\
\text { by the subsurface soil investigation per IBC para. } \\
1802.2 .3\end{array}$ \\
\hline \multirow{3}{*}{$\begin{array}{l}\text { Resistance to Deterioration from } \\
\text { Organisms and Substances in } \\
\text { Contacting Soil }\end{array}$} & Test Method D7281 & Pass \\
\hline & Test Method E154 & $<0.3$ perms water vapor permeability \\
\hline & $\begin{array}{l}\text { Test Specification } \\
\text { E1745 }\end{array}$ & $\begin{array}{l}\text { Section } 7 \text { (using a } 3 \text { in. thick precast concrete } \\
\text { paver in lieu of cast-in-place concrete). }\end{array}$ \\
\hline \multirow{2}{*}{$\begin{array}{l}\text { Adhesion to Substrate (Except for } \\
\text { Grade 1, Class 2) }\end{array}$} & Test Method D7234 & $>1518 \mathrm{kPa}$ [220 psi] using a $50 \mathrm{~mm}$ [2 in.] dolly \\
\hline & Test Method D903 & 3 pli $[535.8 \mathrm{gm} / \mathrm{cm}]$ \\
\hline \multicolumn{3}{|c|}{ Waterproofing Material Physical Properties for bituminous } \\
\hline $\begin{array}{l}\text { Low Temperature Unrolling Type } \\
\text { 1A }\end{array}$ & Test Method D5636 & No Cracking at $0^{\circ} \mathrm{C}\left[32^{\circ} \mathrm{F}\right]$ \\
\hline Crack Bridging & Test Method D5849 & $\begin{array}{l}500 \text { cycles select appropriate temperature for the } \\
\text { weather conditions for which the membrane is } \\
\text { applied. }\end{array}$ \\
\hline Flexibility & Test Method D5683 & No Cracking \\
\hline Water Absorption & Test Method D95 & $\begin{array}{l}<2 \% \text { by weight. Run } 45 \text { cycles of immersion in } \\
\text { water at } 23^{\circ} \mathrm{C} \text { and } 50{ }^{\circ} \mathrm{C}\left[73^{\circ} \mathrm{F} \text { and } 122^{\circ} \mathrm{F}\right] \text { for } \\
24 \mathrm{~h} \text { for start of test and after } 45 \text { th cycle. }\end{array}$ \\
\hline \multicolumn{3}{|c|}{ Waterproofing Material Physical Properties for Non-bituminous Organic } \\
\hline \multirow[b]{2}{*}{ Water Absorption } & Test Method D570 & $<3 \%$ by weight when tested per Section $7 \mathrm{~A}$ \\
\hline & Test Method D471 & $\begin{array}{l}<3 \% \text { by weight when tested per Section } 12 \text { at } \\
\qquad 23^{\circ} \mathrm{C}\left[73^{\circ} \mathrm{F}\right] \text { for } 2998 \mathrm{~h}\end{array}$ \\
\hline $\begin{array}{l}\text { Linear Dimension Change } \\
\text { (PVC only) }\end{array}$ & Specification D4551 & $<5 \%$ at $70^{\circ} \mathrm{C}\left[158^{\circ} \mathrm{F}\right] 1 \mathrm{~h}$ per Test Method D1204 \\
\hline Extensibility After Heat Aging & Test Method C1522 & $6.4 \mathrm{~mm}[1 / 4 \mathrm{in}]$. \\
\hline Crack Bridging Ability & Test Method C1305 & No Cracking \\
\hline $\begin{array}{c}\text { Low Temperature Flexibility and } \\
\text { Crack Bridging for } \\
\text { Liquid-Applied Membranes }\end{array}$ & Test Method C1305 & Pass \\
\hline Resistance of Plastics to Bacteria & Specification D4551 & No effect 12 of 12 samples pass \\
\hline Resistance to Chemical Reagents & Practice D896 & $\begin{array}{l}\text { No delamination, blistering, emulsification, or } \\
\text { (undiluted deterioration } 15 \mathrm{~N} / 5 \mathrm{P} / 5 \text { Potash) }\end{array}$ \\
\hline Resistance to Petroleum & $\begin{array}{l}\text { Test Methods E154 } \\
\text { Section } 14\end{array}$ & $<0.3$ perms \\
\hline
\end{tabular}

\subsection{Waterproofing in Negative and Positive Side on Underground Structures}

When it comes to the selection of waterproofing materials and methods, there has historically always been concerns with the selection of the material/method for new construction and design to avoid long term problems that concern with structural durability, leakage, and RH level in underground structures. However, as waterproofing construction cost relies mostly one application during construction, rather than material properties, designers, building owners, and constructors are opting to choose materials that are easier to handle during construction to reduce construction time 
and costs [25]. In this regard, cementitious materials are generally much easier to handle than liquid membrane which is why this material may be used, and performance wise there should not be far too much of a difference when appropriate environmental conditions are met [25]. However, certain waterproofing materials such cementitious materials face various types of problems such as cracking, spalling, and absorption of moisture when used in high temperature/ humidity regions or areas where high water level is expected. Experts may know when to avoid using these materials from experience, but this knowledge is not readily available in a quantifiable data or statistics in an international setting, which is why in many cases, home owners still opt to use materials inappropriate to the construction conditions to reduce construction time/costs. In many cases, negative-side waterproofing is preferred to reduce construction costs and facilitate waterproofing installation [26]. While cost efficiency is certainly a factor for a successful completion of new concrete structure projects, cost reduction may risk reduced quality and durability life-cycle of the structure. Precise identification of environmental degradation factors is not always taken into account, which can lead to selection of inappropriate materials or waterproofing methods. Many of such incidents document cases that resulted in unintended and unexpected rise of maintenance and repair costs that include problems related to reinforcing steel corrosion and water leakage of concrete structures [26]. A concise classification of waterproofing materials in accordance to waterproofing materials applied on different sides of the concrete wall is difficult [27]. Refer to Figure 4 for an illustration on different types of waterproofing installation methods.

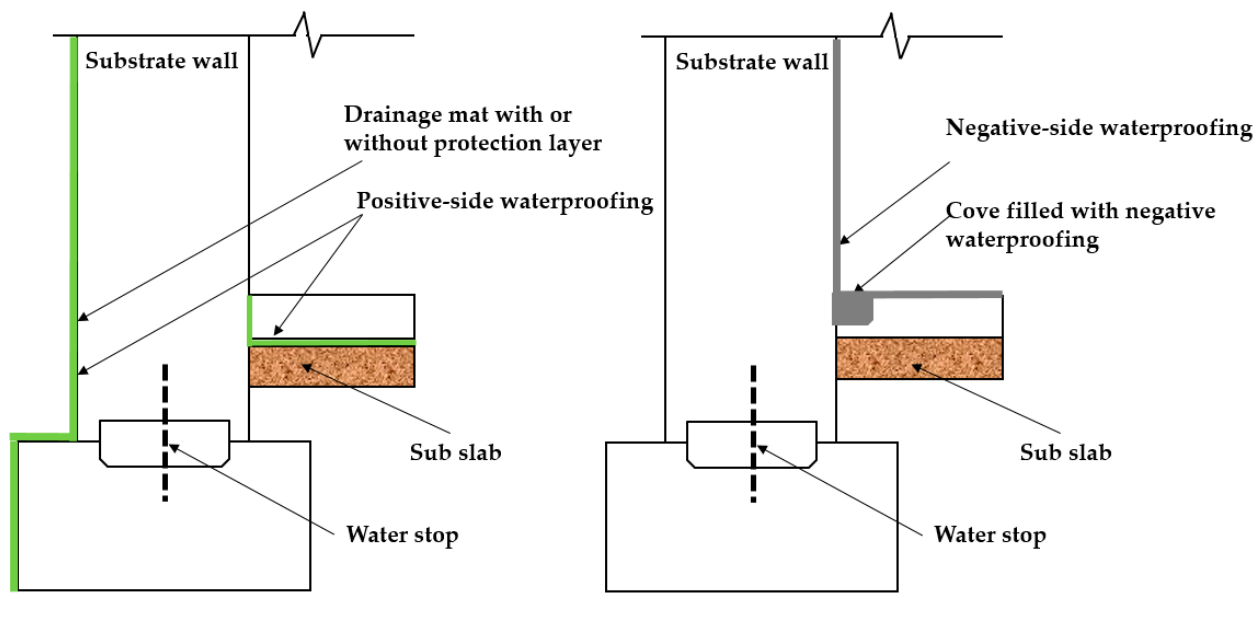

(a)

(b)

Figure 4. Waterproofing installation methods in below-grade concrete structures [5]; (a) positive- side waterproofing design and $(\mathbf{b})$ negative-side waterproofing design.

\subsubsection{Waterproofing Materials Commonly used in Positive Side Waterproofing}

For positive side waterproofing system (Refer to Figure 5a)), there are fluid-applied type and sheet membrane type. Most fluid-applied types are advantageous in that they are self-flashing and can be applied in a continuous, seamless layer [28]. Recently developed materials have also resolved previous workability problems related to securing even thickness, the environmental protection policies have prompted the replacement of hazard chemical additives that were originally added into the materials [29]. However, high cost and prolonged construction time are factors to consider, especially in below-grade construction where quality installation is dependent highly on skilled and experienced workmanship [30]. Sheet membrane systems, on the other hand, are generally cheaper and quicker to install compared to fluid-applied type systems, but require more detailed attention for vertical spaces, protruded areas, and small confined areas. Seams and overlap sections are often more vulnerable to degradation and prone to forming leakage paths, and the quality of the waterproofing performance is highly dependent on the condition of the seam or overlap installation sections, thus reinforcing work 
is more emphasized in these areas [30]. For this demonstration study, a fluid-applied type urethane waterproofing material with the least amount of inconsistent variable for installation was selected for evaluation. Material type selected is compliant to the standard performance criteria of KS F 3211.

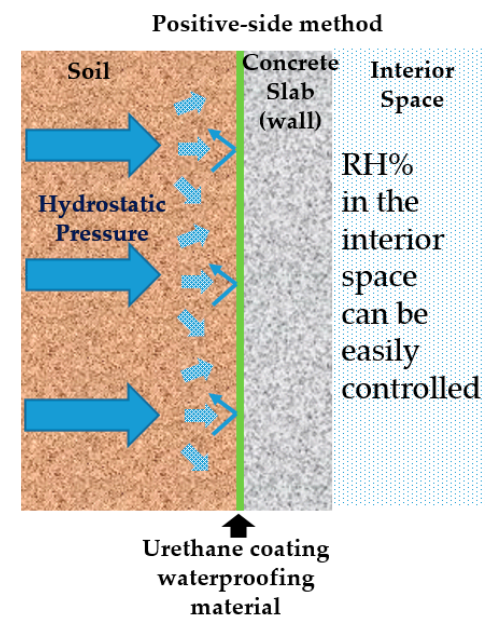

(a)

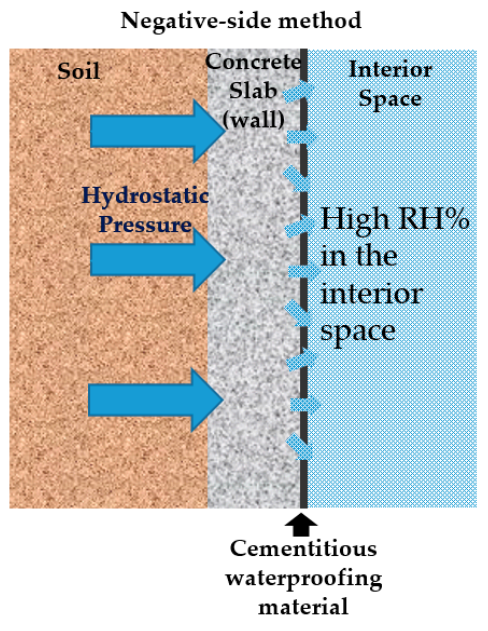

(b)

Figure 5. Hydrostatic pressure on the different types of waterproofing methods; (a) positive-side waterproofing material (cementitious) and (b) negative-side waterproofing (urethane).

\subsubsection{Waterproofing Materials Commonly used in Negative Side Waterproofing}

For negative side waterproofing system (Refer to Figure 5b)), there are capillary systems and acrylic modified cementitious waterproofing materials [30]. Cementitious waterproofing materials or capillary systems (henceforth called cementitious waterproofing) are applied through coating, and the impregnation into the pores of the concrete substrate matrix allows an integrated installation that provides a water repellent property to the concrete substrate [29]. Cementitious waterproofing materials allow the intrusion of water into the concrete pores as the hydrophilic reaction is necessary for admixtures to close off the pores in the concrete. While this forms a protection against hydrostatic pressure, when saturated these systems are subject to risk of freeze-thaw degradation effects. The acrylic modified cementitious type coating (henceforth called cementitious type) is most commonly used. Installation is comprised of brush or trowel application on concrete or masonry surfaces [28]. Cementitious type materials have strong bonding mechanism even on wet substrate surface [28]. However, cementitious systems lack crack bridging and elastomeric properties, and below-grade concrete structures are often subject to freeze-thaw cycling and structural settlement, and cause movement in joints and cracks [29].

\subsection{Proposal of Evaluation Criteria Based on Risk Factors Due to High RH in Concrete Structures}

The factors discussed in the above stresses the importance of evaluating the condensation level of concrete structures, and the potential to mitigate these risks through selection of optimal waterproofing material and method. As such evaluation method has yet to be devised, this paper proposes such method. The following sections outline demonstrates an evaluation regime of assessing the RH control performance of waterproofing material and method (positive side installed liquid applied membrane and negative side installed cementitious waterproofing material) installed onto an underground structure. The humidity control performance is evaluated in compliance to a $\mathrm{RH}$ limit of $70 \%$ * in accordance to the KOREA LAND \& HOUSING CORPORATION(LH) building specification in Korea [31]. Furthermore, a relative comparison of performance criteria with regards to maintenance capacity of RH through a linear regression analysis of the measured data, and a cumulative probability density analysis to derive the approximate maximum and minimum range of $\mathrm{RH}$ for each waterproofing material and method is used to conduct a comprehensive comparison of RH control performance. 
( ${ }^{*}$ Note: Should this evaluation method be adopted elsewhere, performance criteria for RH limit should accord the relevant national standards.)

\section{Proposed Evaluation Method for RH Control Performance of Waterproofing Materials}

In this study, an evaluation method was designed to observe and analyze the RH changes of the negative side of the concrete wall in accordance to different waterproofing method after applying a fixed temperatures compliant to seasonal characteristics. In this demonstration, the average, intercept derived from linear regression analysis of RH measurement and maximum RH are used as the means to derive an evaluation criterion, and these parameters compared between specimens installed with different waterproofing conditions. First, a mortar substrate specimen untreated with waterproofing is used as an obvious base of verification that waterproofing protection in concrete substrates affect the humidity level in the interior, and a basis for comparison with the specimens installed with waterproofing materials. The waterproofing material installed specimen are prepared in the following respective conditions; (1) positive-side applied liquid membrane and (2) negative-side applied cementitious coating. Based on the results, an assessment will be conducted to state which waterproofing materials and method type can provide the most adequate conditions for humidity control for quality maintenance purposes.

\subsection{Experimental Equipment}

For the temperature and humidity measurement equipment, a sensor that can measure in $0-1$ VDC, $0-5$ VDC, and 0-10 VDC ranges was used. The sensor was connected to a multichannel data logger wherein the RH level could be measured. The specifications of the sensor and data logger used in the testing are shown in Tables 2 and 3, respectively, below.

Table 2. Temperature and humidity sensor specification.

\begin{tabular}{cc}
\hline Item & Criteria \\
\hline RH Range & $0 \sim 100 \% \mathrm{RH}$ \\
Temperature Range & $0 \sim 100{ }^{\circ} \mathrm{C},-20 \sim 80{ }^{\circ} \mathrm{C}$ \\
Precision at $23{ }^{\circ} \mathrm{C}$ & $< \pm 2 \% \mathrm{RH}(10 \sim 99 \% \mathrm{RH})$ \\
Annual RH Stability & $< \pm 1 \% \mathrm{RH}$ \\
RH reaction time & $<10 \mathrm{~s}$ (up to $90 \%)$ \\
Signal Measurement & $0-1 \mathrm{VDC}, 0-5 \mathrm{VDC}, 0-10 \mathrm{VDC}$ \\
Size & Length: $80 \mathrm{~mm}, \mathrm{C} 12 \mathrm{~mm}$ \\
\hline
\end{tabular}

Table 3. Data logger specification.

\begin{tabular}{cccccc}
\hline Item & Support & Photo \\
\hline DCV Precision & $0.004 \%$ / Year & \\
Max. Scanning Speed & 250 channels $/ \mathrm{sec}$ & \\
\hline
\end{tabular}




\subsection{Specimen Assembly for Evaluation}

\subsubsection{Waterproofing Specimen}

Waterproofing specimens were designed to simulate the respective waterproofing installation methods of positive and negative side waterproofing. Specimen substrate was prepared with mortar (W/C ratio: 55\%) in accordance to the method outlined in KS L 5207. A $\varnothing 100 \mathrm{~mm}$ by $80 \mathrm{~mm}$ mold is prepared, and fresh mortar is cast into the mold, and cured in the laboratory for 24 hours under the ambient conditions $\left(20 \pm 2{ }^{\circ} \mathrm{C}, 65 \% \mathrm{RH}\right)$. The mold is removed from the hardened mortar and is then placed in water for seven days at $20 \pm 3^{\circ} \mathrm{C}$. Next, the mortar substrate is placed in the temperature chamber again, the ambient condition set at $20 \pm 3{ }^{\circ} \mathrm{C}, 65 \% \mathrm{RH}$. Once the mortar substrate is fully cured, the waterproofing materials are installed on to the respective side of the waterproofing installation specification.

The three types of specimen (Specimens A, B, and C) were made for evaluation. For Specimen A, $3 \mathrm{~mm}$ thick layer fluid-applied type urethane waterproofing material (coating) was installed and for Specimen B, $8 \mathrm{~mm}$ thick layer cementitious waterproofing material (coating) was applied (among the existing thickness range for waterproofing layer installation specifications, the maximum thickness was selected to ensure the highest quality application condition for the respective material type). For this demonstration study, cementitious type material with the least amount of inconsistent (with factors including mixture ratio, usage cases based on domestic survey, application method taken into consideration) variable for installation was selected for evaluation. Material type selected is compliant to the standard performance criteria of KS F 4919. For Specimen C, waterproofing membrane was not installed. Specimen $C$ was specifically studied and evaluated for reference purposes to display the results of what would happen with the RH level in the negative side of the wall of waterproofing materials are not used. Refer to Figure 6 below for illustration.

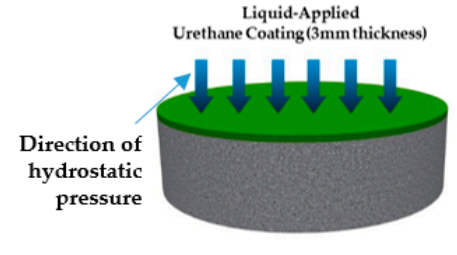

Specimen A

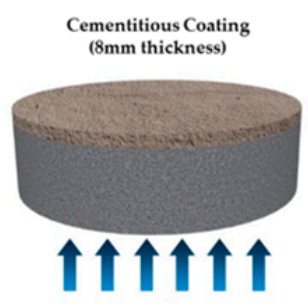

Specimen B

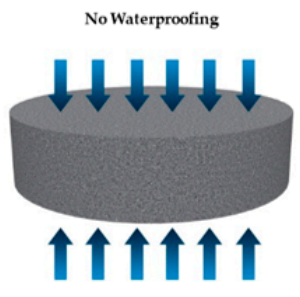

Specimen C

Figure 6. Waterproofing specimens respectively installed with waterproofing materials.

\subsubsection{Acrylic Apparatus Assembly of Waterproofing Specimens for RH Measurement}

The three types of specimen are placed between the acrylic apparatus, and the seam joints are covered with silicone sealants. The designated side of the humidity measurement acrylic apparatus representing the negative side of the structure is covered with a metallic cover. On the other side of the acrylic apparatus structure, the metallic cover has a $1 \mathrm{~cm}$ hole in the center through which the temperature and humidity sensor is installed. The sensor is then connected to the data logger, and the RH measurement data taken and recorded for analysis. Refer to the below Figure 7 for illustration.

\subsection{Test Condition Setting for Estimation of Humidity Change Performance of Waterproofing Materials}

For this evaluation demonstration, the temperature conditioning for the testing was set in accordance to the average temperatures of winter, spring/autumn, and summer season respectively, and the variable was in compliance to the statistics derived from Korea Meteorological Administration on Monthly Weather Report in Korea 2018 [32]. 


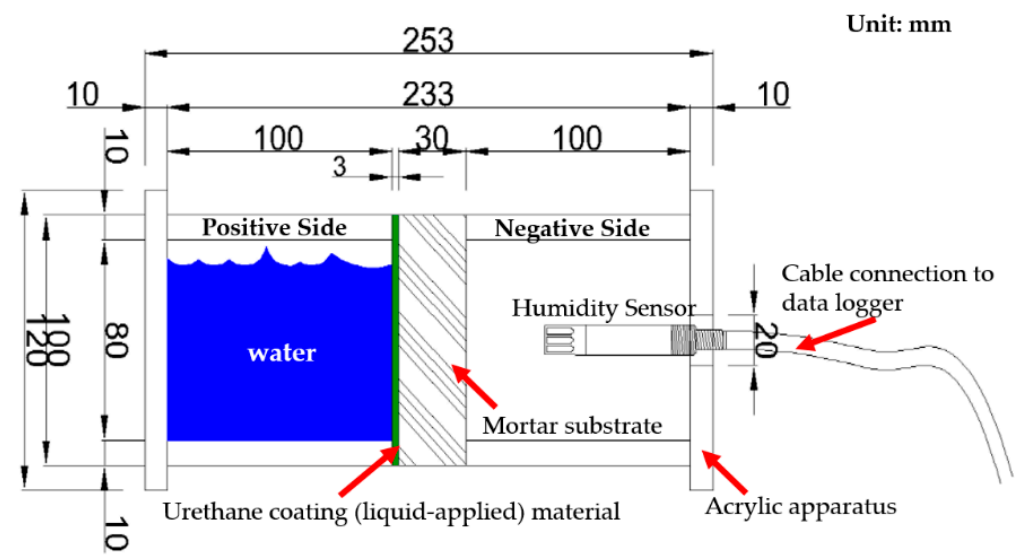

(a)

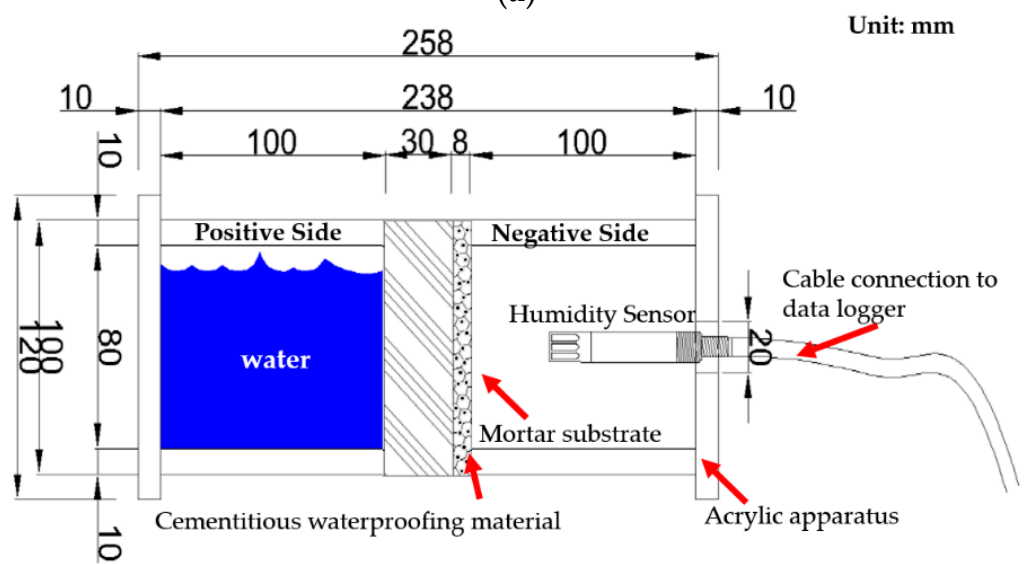

(b)

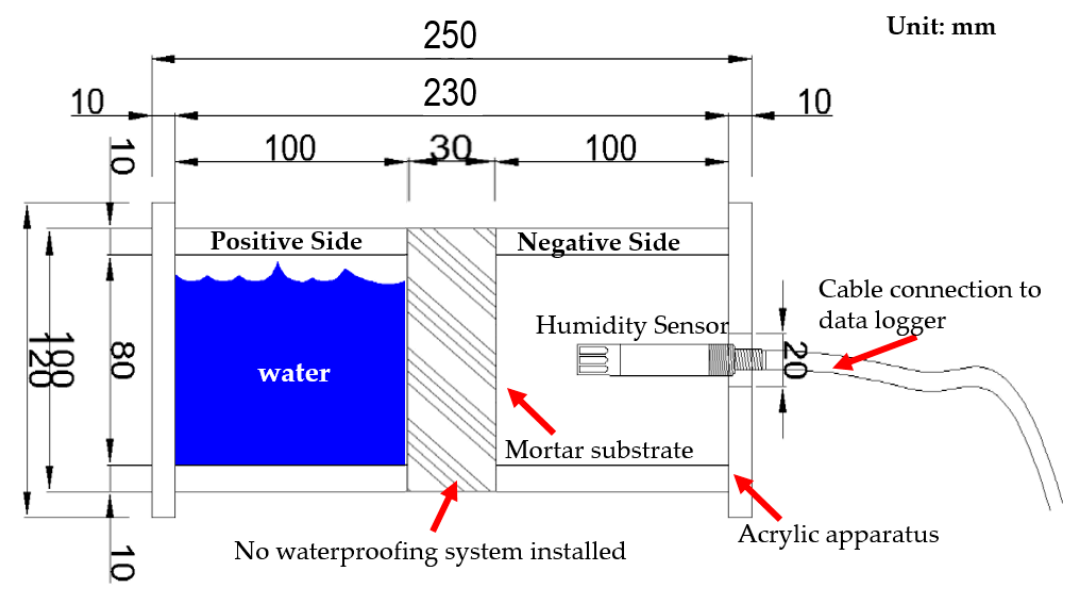

(c)

Figure 7. Illustration and dimensions of apparatus of waterproofing specimen; (a) Specimen A apparatus: Urethane coating (liquid applied), (b) Specimen B apparatus: Cementitious coating, and (c) Specimen $\mathrm{C}$ apparatus: Untreated.

(1) Winter season temperature for test conditioning $\left(4^{\circ} \mathrm{C}\right)$

The average temperature during winter season (from December to February [32]) ranges from subzero $-15^{\circ} \mathrm{C}$ to $-10^{\circ} \mathrm{C}$. However, according to the "Standard Specification of Building Construction," public below-grade structure interior conditions are required to be above $4{ }^{\circ} \mathrm{C}$ at all times to avoid the 
freezing point of water. Therefore, in this study, the temperature conditioning for testing was set at $4{ }^{\circ} \mathrm{C}$ for winter temperature conditioning.

(2) Spring and fall season temperature for test conditioning $\left(20^{\circ} \mathrm{C}\right)$

The average temperature during spring and fall seasons ranges between $15-20^{\circ} \mathrm{C}$ during spring (March to May) and autumn season (September to November) [32]. Therefore, in this study, the temperature conditioning for testing was set at $20^{\circ} \mathrm{C}$ for both the spring and autumn.

(3) Summer season temperature for test conditioning $\left(40^{\circ} \mathrm{C}\right)$

The average temperature during summer season ranges between $30-40^{\circ} \mathrm{C}$ during the summer season (June to August) [32]. To simulate the highest possible temperature condition that can be found in Korea for this study, the temperature conditioning for testing was set at $40^{\circ} \mathrm{C}$. (Note: The conditions outlined above was selected out of lack of standardized regulation for temperature conditions for testing and only serves as a reference value. If this evaluation method is to be conducted elsewhere, Temperature values are subject to change according to different national standards. Examples may include warmer countries with ranges that can reach up to $(27 \pm 2)^{\circ} \mathrm{C}$ and colder countries at $(16 \pm 3){ }^{\circ} \mathrm{C}$, etc. The same applied to humidity conditions.)

\subsection{Data Collection for the Acrylic Apparatus}

Test apparatus of waterproofing specimens (refer to Figure 8) were placed inside chamber with temperature conditioning set in accordance to the respective seasons (winter, spring/autumn, and summer). The humidity change was recorded in a data logger whose collection interval rate was set to be once every $1200 \mathrm{~s}^{*}$.

\subsubsection{Humidity Level Changes of Waterproofing Membrane Installation Methods}

The humidity level changes over 798 intervals was measured, and the data was collected using the data logger connected to the humidity sensor. The humidity measurements of the three types of installed specimens were expressed in a line graph in accordance to the seasonal temperature parameters for a) winter, b) spring and autumn, and c) summer in Figure 8, and the results clearly showed the difference in $\mathrm{RH}$ conditions of each waterproofing membrane installation methods.

In the winter season $\left(4^{\circ} \mathrm{C}\right)$ condition (refer to Figure 8a)), there was very little change of $\mathrm{RH}$ with Specimen A with a declining trend, starting at approximately $53 \% \sim 55 \% \mathrm{RH}$ range. In the case of Specimen B, a moderate rise in the RH could be observed at the starting interval during the testing period. This increase was observed approximately between from 0 to $300^{\text {th }}$ interval, and the RH range stabilized, staying at around 7\%6-77\%. In the case of Specimen C, even sharper increase of RH was detected, from $40^{\text {th }}$ measurement interval to $60^{\text {th }}$, and stabilizing at a high $\mathrm{RH}$ range of approximately $90 \%$ until the end of the testing period.

In the spring/autumn season $\left(20^{\circ} \mathrm{C}\right.$ ) condition (refer to Figure $\left.8 \mathrm{~b}\right)$ ), a very similar pattern was observed for all specimen types, but RH stabilizing point was different with Specimen A and B. Specimen A RH measurement stabilized at approximately $57 \%-58 \%$ range, while with Specimen B the RH stabilization point began more closely at the $400^{\text {th }}$ measurement interval, at approximately $80 \%$. In the case of Specimen C, the RH range stayed at approximately $90 \%$ again from the beginning (with a sharp rise at the start) to the end of the testing period.

In the summer season $\left(40{ }^{\circ} \mathrm{C}\right.$ ) condition (refer to Figure $\left.8 \mathrm{c}\right)$ ), the starting $\mathrm{RH}$ measurement trends were observed to be more curved, with an increase of $\mathrm{RH}$ to approximately $70 \%$ and decreasing stabilization of $63 \%-64 \%$ with Specimen A. In the case of Specimen B however, a distinct trend of increase in $\mathrm{RH}$ was observed, eventually reaching the same level of $\mathrm{RH}$ of approximately $90 \%$ as with Specimen $C$ from the $750^{\text {th }}$ measurement interval and onwards.

Overall, the RH of the Specimen C was the highest, reaching on average $77 \%-90 \%$ during all seasons. Specimen A was able to maintain a stable $\mathrm{RH} \%$ below $70 \%$ in all three seasonal temperatures. In the case of Specimen B however, it was shown that in the winter season, the RH measurement showed a steady increase from a below $70 \%$ to as much as above $80 \%$. 


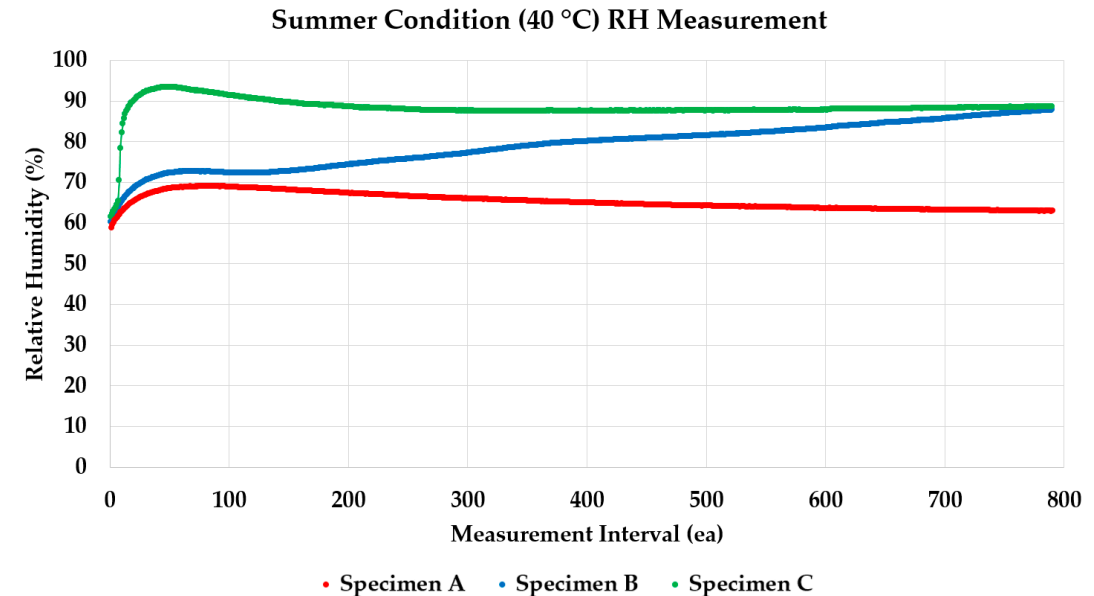

(a)

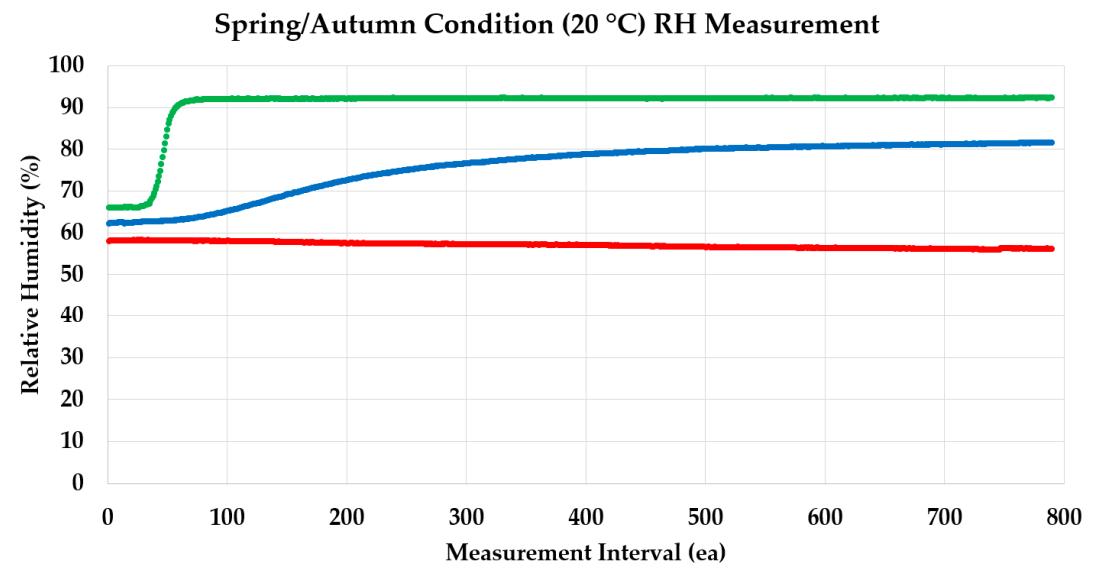

- Specimen A - Specimen B - Specimen C

(b)

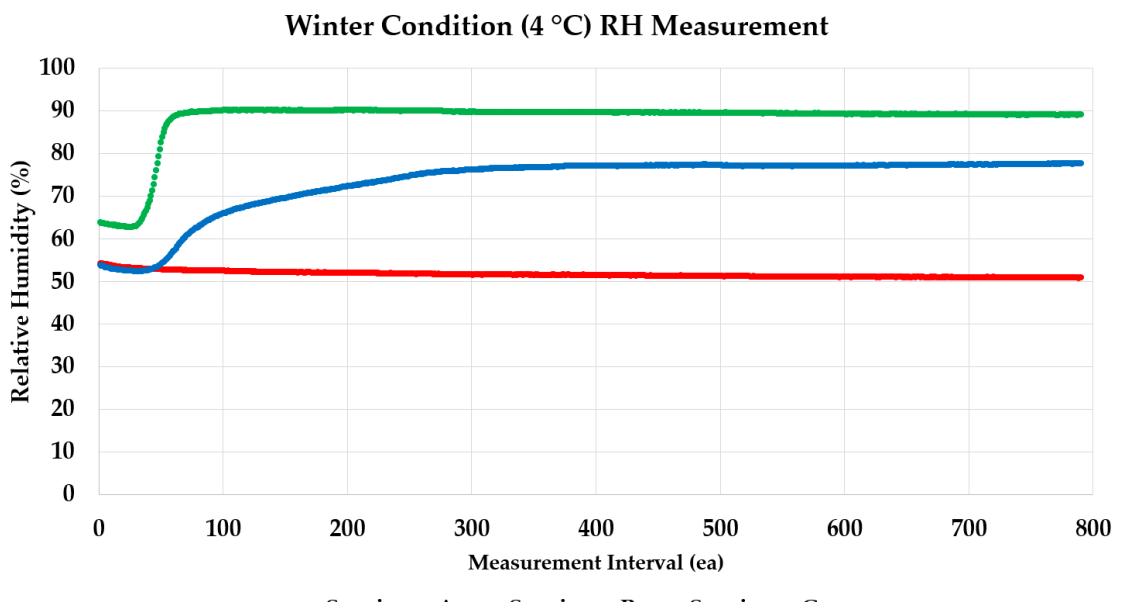

- Specimen A - Specimen B - Specimen C

(c)

Figure 8. Test method demonstration experimental results; (a) winter temperature condition results, (b) autumn/spring temperature condition results, and (c) summer temperature condition results.

From this analysis results, Specimen A would be the only waterproofing material and installation type that can meet the requirement of the LH Building Construction specification standard criteria. 
While this was an expected result with Specimen $C$ as it was untreated with a waterproofing material, Specimen B was able to demonstrate some level of RH humidity control performance in comparison due to the waterproofing layer, and the increase in the $\mathrm{RH}$ was not as apparent. However, in high temperature condition, the RH eventually reached the same level as it would with the case of Specimen C. This phenomenon expectedly indicates that cementitious waterproofing material and untreated substrate layer allows almost immediate moisture penetration into the interior space without any reinforcing insulation layer, as there is an obvious indication that the saturation of water in the substrate affected the interior RH level. In comparison, Specimen A maintained the lowest RH throughout all of the seasonal temperature conditioning.

To analyze the RH control performance with regards to changing RH throughout the testing period, a linear regression graph was derived to analyze the RH maintenance tendency for each specimen type under the respective seasonal temperature conditions. The maintenance tendency is determined by the slope and the intercept values obtained from the regression lines and this performance trait is compared between the specimen types. Refer to Figure 9 and Table 4 below for details.

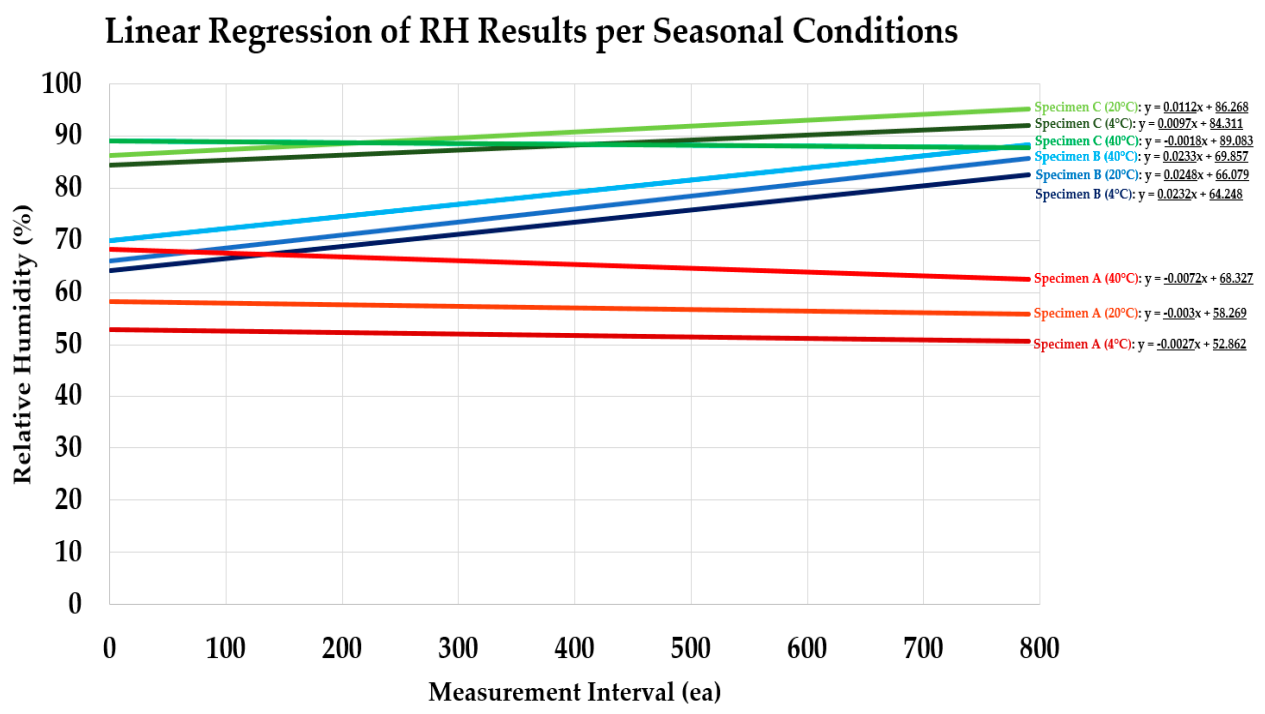

Figure 9. Slope calculation through regression line of relative humidity $(\mathrm{RH})$ measurement results.

Table 4. Slopes and intercepts derived through regression line of RH measurement results.

\begin{tabular}{ccccccc}
\hline \multirow{2}{*}{$\begin{array}{c}\text { Specimen } \\
\text { Types }\end{array}$} & \multicolumn{5}{c}{ Seasonal Conditions } \\
\cline { 2 - 6 } & \multicolumn{2}{c}{ Winter $\left(\mathbf{4}^{\circ} \mathbf{C}\right)$} & \multicolumn{1}{c}{ Spring/Autumn $\left(\mathbf{2 0}{ }^{\circ} \mathbf{C}\right)$} & \multicolumn{2}{c}{ Summer $\left(\mathbf{4 0}{ }^{\circ} \mathbf{C}\right)$} \\
\hline & Slope & Intercept (\%) & Slope & Intercept (\%) & Slope & Intercept (\%) \\
\hline $\mathrm{A}$ & $-2.7 \times 10^{-3}$ & 52.862 & $-3 \times 10^{-3}$ & 58.269 & $-7.2 \times 10^{-3}$ & 68.327 \\
$\mathrm{~B}$ & $2.32 \times 10^{-2}$ & 64.248 & $2.48 \times 10^{-2}$ & 66.079 & $2.33 \times 10^{-2}$ & 69.857 \\
$\mathrm{C}$ & $-9.7 \times 10^{-3}$ & 84.311 & $1.12 \times 10^{-2}$ & 86.268 & $-1.8 \times 10^{-3}$ & 89.083 \\
\hline
\end{tabular}

According to the slope derivation results, every specimen had a relatively consistent slopes, but some distinct tendencies could still be observed for each specimen types. Specimen A had a declining slope for all three seasonal conditions. This result could indicate that the RH can be expected to be easily controlled owing to the observation that the RH level stabilizes and decreases overtime despite the continued exposure to water at the positive side of the substrate. In contrast, Specimen B had inclining slopes for all seasonal conditions, indicating that even though initial RH may be similar to that of Specimen A, increase of RH in the interior space can be expected. In case of Specimen C, varying results from declining to inclining slopes were observed, but from comparing the intercept values, the $\mathrm{RH}$ level was far above the permissible level of RH (in accordance to the LH Building Construction specification). The results verify that positive-side installed urethane coating waterproofing membranes 
(Specimen A) had the most stable RH maintenance performance, remaining at below the required $\mathrm{RH}$ criteria. Whereas with the negative-side installed cementitious waterproofing material, it is expected that eventually the RH will consistently increase overtime due to the exposure of continued hydrostatic pressure.

\subsubsection{Parameter Analysis (Average, Slope Intercept, and Maximum) Measured RH and Comparison}

Lastly, the average, and maximum $\mathrm{RH}$ was calculated from the data intervals derived Figure 8 , and the intercept was derived directly from the linear regression line equations from Figure 9 between the results of the three separate seasons, and the recorded results are outlined in Table 5 below.

Table 5. RH (average, intercept, and maximum) measurement for each specimen types in accordance to seasonal conditions.

\begin{tabular}{|c|c|c|c|c|c|c|c|c|c|}
\hline \multirow{3}{*}{$\begin{array}{l}\text { Specimen } \\
\text { Types }\end{array}$} & \multicolumn{9}{|c|}{ Average, Intercept and Maximum of RH Measurement per Seasonal Conditioning } \\
\hline & \multicolumn{3}{|c|}{ Winter $\left(4^{\circ} \mathrm{C}\right)$} & \multicolumn{3}{|c|}{ Spring/Autumn $\left(20^{\circ} \mathrm{C}\right)$} & \multicolumn{3}{|c|}{ Summer $\left(40^{\circ} \mathrm{C}\right)$} \\
\hline & $\begin{array}{l}\text { Avg. } \\
(\%)\end{array}$ & $\begin{array}{c}\text { Intercept } \\
(\%)\end{array}$ & $\begin{array}{l}\text { Max } \\
(\%)\end{array}$ & $\begin{array}{l}\text { Avg. } \\
(\%)\end{array}$ & $\begin{array}{c}\text { Intercept } \\
(\%)\end{array}$ & $\begin{array}{l}\text { Max } \\
(\%)\end{array}$ & $\begin{array}{l}\text { Avg. } \\
(\%)\end{array}$ & $\begin{array}{c}\text { Intercept } \\
(\%)\end{array}$ & $\begin{array}{c}\operatorname{Max} \\
(\%)\end{array}$ \\
\hline A & 51.78 & 52.86 & 54.42 & 57.10 & 58.27 & 58.31 & 65.47 & 52.86 & 69.16 \\
\hline $\mathrm{B}$ & 73.42 & 64.25 & 77.79 & 75.87 & 66.08 & 81.64 & 79.06 & 69.86 & 87.85 \\
\hline C & 88.14 & 84.31 & 90.25 & 90.69 & 86.27 & 92.41 & 88.38 & 89.08 & 93.43 \\
\hline
\end{tabular}

Based on the recorded $\mathrm{RH}$ change measurement related factors, a comprehensive evaluation was conducted to compare the ease of humidity control in the negative side of the below grade structure based on the waterproofing method used. For this, a radar chart based on the three different factors (average, intercept and maximum) was derived in accordance to different seasonal temperature conditions in Figure 10. The maximum range of the radar chart was set to $100 \% \mathrm{RH}$ and the recorded data was plotted on the graphs. For each factor, the higher values indicate that the $\mathrm{RH}$ change conditions are not moderate, and could indicate difficulty in humidity control using conventional methods using electrical facilities and equipment. The yellow region in all of the radar charts indicate the permissible $\mathrm{RH}$ range in accordance to the LH Building Construction specification (below $\mathrm{RH}$ level of $70 \%$ ).

In the winter season $\left(4^{\circ} \mathrm{C}\right)$ condition (refer to Figure 10a)), it was observed that for Specimen A, the RH level with regards to average value (51.78\%), slope intercept (52.86\%), and maximum $\mathrm{RH}$ $(54.42 \%)$ was all able to be within the $70 \%$ RH range limit, complying to the LH Building Construction specification standard criteria. With Specimen B, the average (73.42\%) and maximum (77.79\%) measured RH were above the $70 \%$ RH standard criteria, but the intercept $(64.25 \%)$ was within the standard criteria range, indicating that throughout the testing period, $\mathrm{RH}$ control performance in the earlier period with minimal exposure to water can be expected. In the case of Specimen $\mathrm{C}$, all three parameters were outside of the $70 \% \mathrm{RH}$ standard criteria $(88.14 \%, 84.31 \%$, and $90.25 \%$, respectively).

In the spring/autumn season $\left(20^{\circ} \mathrm{C}\right.$ ) condition (refer to Figure $\left.\left.10 \mathrm{~b}\right)\right)$, Specimen $\mathrm{A}$ again met the required performance criteria for all three parameters $(57.10 \%, 58.27 \%$, and $58.31 \%$, respectively), and Specimen B was able to meet the standard criteria for the slope intercept (66.08\%) again, but the deviation from the standard criteria was marginally higher than the winter condition results, especially in the case with maximum measured $\mathrm{RH}(81.64 \%)$. In the case of Specimen $\mathrm{C}$, all three parameters were again outside of the $70 \% \mathrm{RH}$ standard criteria $(90.69 \%, 86.27 \%$, and $92.41 \%$, respectively).

In the summer season $\left(40{ }^{\circ} \mathrm{C}\right.$ ) condition (refer to Figure $\left.10 \mathrm{c}\right)$ ), Specimen A met the required performance criteria for all three parameters, but the average and maximum $\mathrm{RH}$ were higher $(65.47 \%$ and $69.16 \%$, respectively). In the case of Specimen B, the RH measurement result for the intercept was barely able to meet the standard criteria (69.86\%) with the deviation from the standard criteria was much higher than the previous seasonal temperature conditions $(79.06 \%$ average $\mathrm{RH}$, and $87.85 \%$ maximum $\mathrm{RH}$ ). In the case of Specimen $\mathrm{C}$, all three parameters were again outside of the $70 \% \mathrm{RH}$ 
standard criteria, but the measurement did not increase as much in contrast to the results found with Specimen A and B (88.38\%, 89.08\%, and 93.43\%, respectively).

Winter $\left(4^{\circ} \mathrm{C}\right)$ Condition Comprehensive Evaluation Results DSpecimen A OSpecimen B DSpecimen C
Average RH (\%)

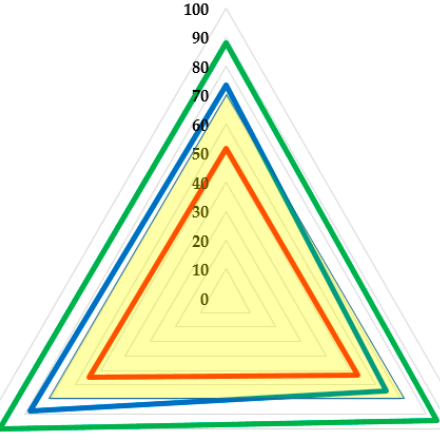

Intercept from Slope Derivation

Maximum RH (\%) RH (\%)

(a)

Autumn/Spring $\left(20^{\circ} \mathrm{C}\right)$ Condition Comprehensive Evaluation Results 口specimen A QSpecimen B QSpecimen C Average RH (\%)

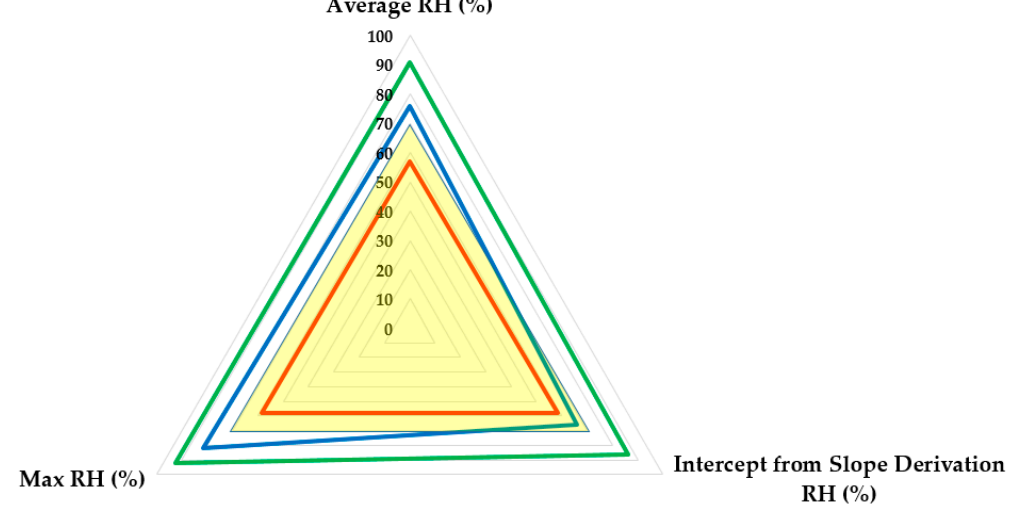

(b)

Summer $\left(40^{\circ} \mathrm{C}\right)$ Condition Comprehensive Evaluation Results

口Specimen A QSpecimen B QSpecimen C Average RH (\%) RH (\%)

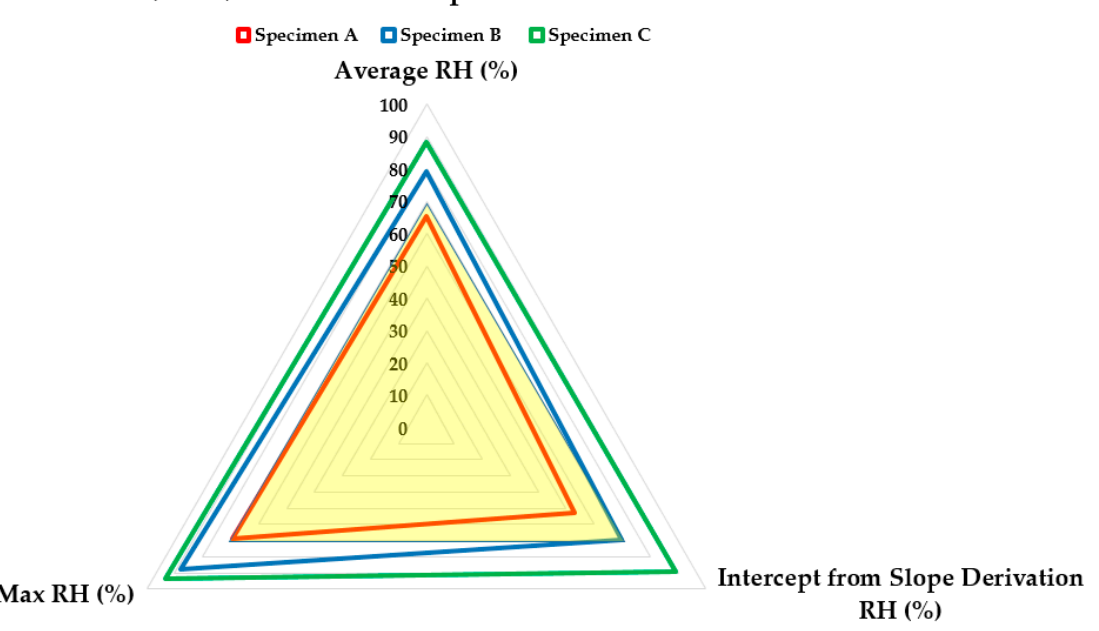

(c)

Figure 10. Cont. 


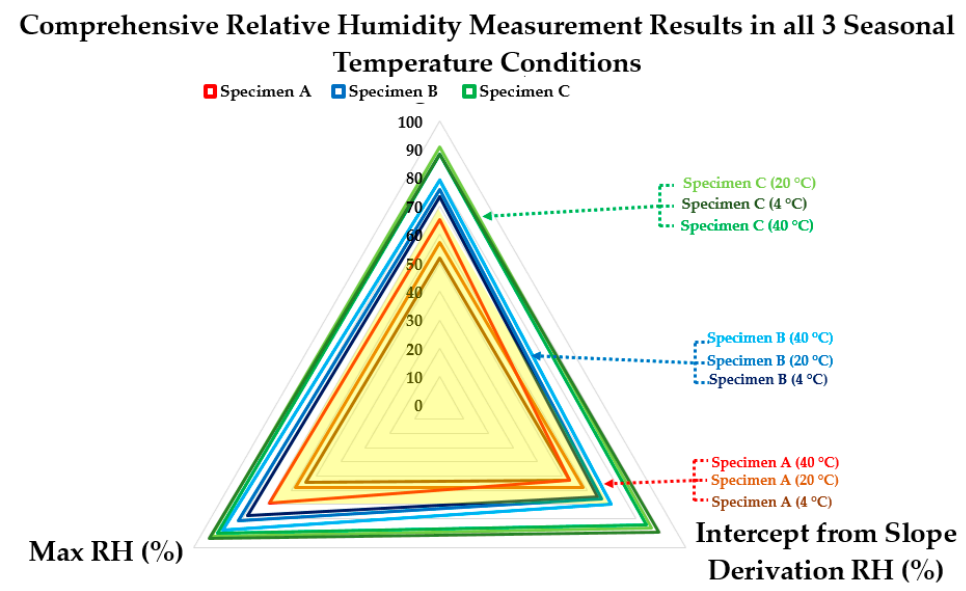

(d)

Figure 10. Average, maximum, and intercept (from slope derivation) RH comparison with respect to standard criteria requirement of three specimen types in accordance to different seasonal temperature conditions; (a) winter condition results; (b) spring/autumn condition results; (c) summer condition results; and (d) comprehensive comparison graph of the three types of specimens.

A comprehensive view (refer to Figure 10d)), of the RH measurement results in all three seasonal temperature conditions with respect to the three parameters show the overall expected RH control performance for the different specimen types. With Specimen A, while a satisfactory performance can be expected throughout the annual cycle, maximum $\mathrm{RH}$ value during summer temperature conditions indicate that supplementary $\mathrm{RH}$ control is necessary to ensure that the RH level in the interior space can maintain below the standard criteria limit of $70 \%$ RH. With Specimen B, it can be inferred from the results that the waterproofing method and material alone is not sufficient to provide a satisfactory $\mathrm{RH}$ control performance throughout the year. Manufacturers and designers should take special care to provide the necessary RH control factors in the structures using this type of waterproofing material and method.

Based on the parameter evaluation, comparing the results of Specimen C (untreated) with Specimen $A$ and $B$ affirm that waterproofing layer affects the $\mathrm{RH}$ control substantially and comparison of Specimen A (positive-side urethane coating) and Specimen B (negative-side cementitious waterproofing) affirm that different $\mathrm{RH}$ control performance can be expected from the respective types of waterproofing material and method.

\subsubsection{Probability Density Analysis of Measured RH}

For further analysis, a normative distribution analysis of the complete RH measurement intervals (798 intervals) was conducted. To derive the probability density of the RH throughout the entire year (comprehensive data obtained from Figure 9) for the respective types of specimens, a probability density analysis of the RH measurement was conducted using the following function;

$$
f\left(x \mid \mu, \sigma^{2}\right)=\frac{1}{\sqrt{2 \pi \sigma^{2}}} e^{-\frac{(x-\mu)^{2}}{2 \sigma^{2}}}
$$

where;

$\mu=$ the mean of distribution of the RH data set

$\sigma=$ standard deviation of the RH data set

$\sigma^{2}=$ variance

Based on the calculation, the following normative distribution graphs were derived for each graph, the results of the three different specimens are displayed (total sample size of 2380 data interval). 
The deviation range was set in the intervals of $1 \%$ range difference of $\mathrm{RH}$, and the frequency for each $\mathrm{RH}$ deviation range was displayed in percentage value.

The probability density analysis displays the overall expected range of the measured $\mathrm{RH}$ results of the three different specimen types throughout the three seasonal temperature conditions. The above comparison of the three different parameters (average, intercept, and maximum $\mathrm{RH}$ ) and slopes is more clearly contrasted through observing the height of the peak within the total range. For the results of the probability density analysis, it is observed that for Specimen A, distinct peaks indicate performance visibly varies between the seasons, but overall is able to maintain the $\mathrm{RH}$ level below $70 \%$ all year round. Expected varying range of $\mathrm{RH}$ is from approximately $50 \%-70 \% \mathrm{RH}$, indicating that the Specimen A is able to provide RH control performance satisfactory to the LH Building Construction standard criteria. In the case of Specimen B, a normally distributed graph can be derived based on the $\mathrm{RH}$ measurement results of all three seasons, but the range of expected $\mathrm{RH}$ varies from low frequency of $52 \% \sim 53 \%$ up to as high as $89 \% \sim 90 \%$ all year round, mostly maintaining the $\mathrm{RH}$ of between $78 \%-79 \%$. In the case of Specimen C (untreated), very low frequency at low RH ranges of $61 \%-67 \%$ could be observed, but the RH range mostly accumulates around the range of $89 \%-95 \%$. Refer to Figure 11 for details;

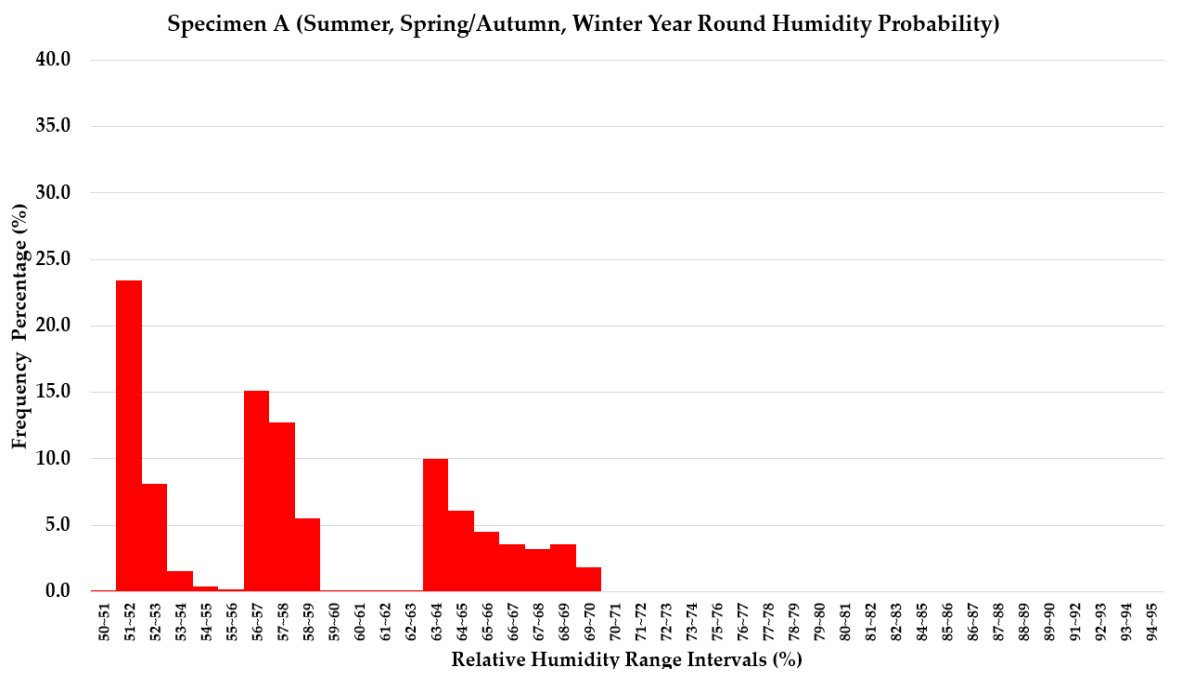

(a)

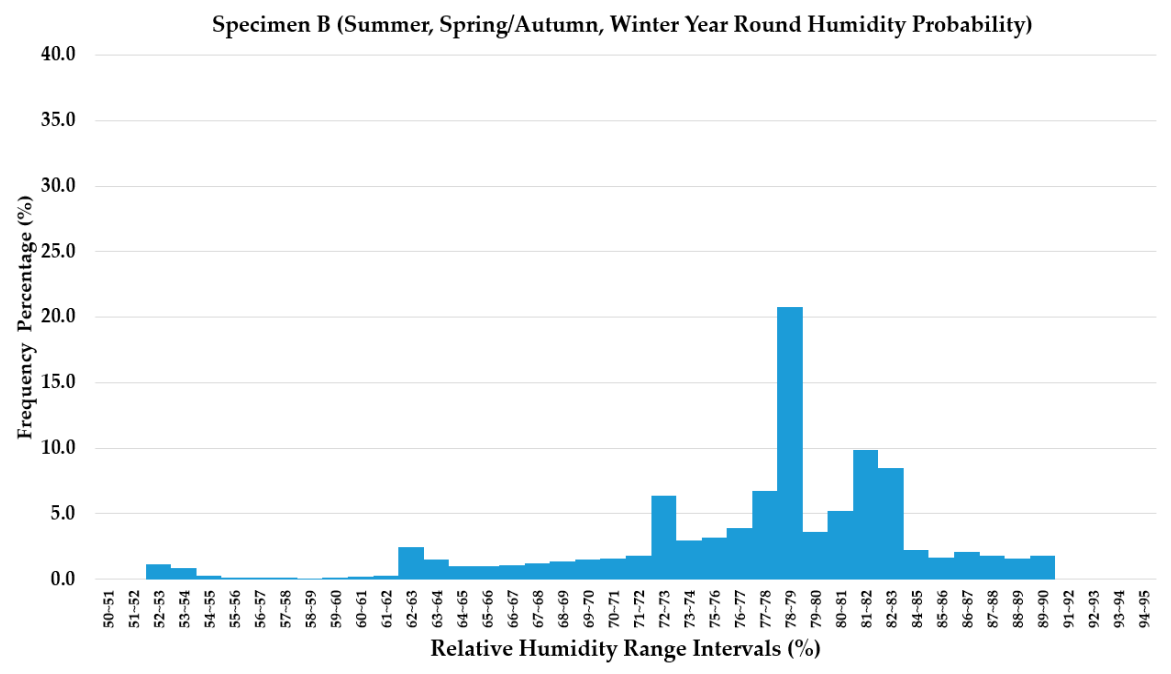

(b)

Figure 11. Cont. 


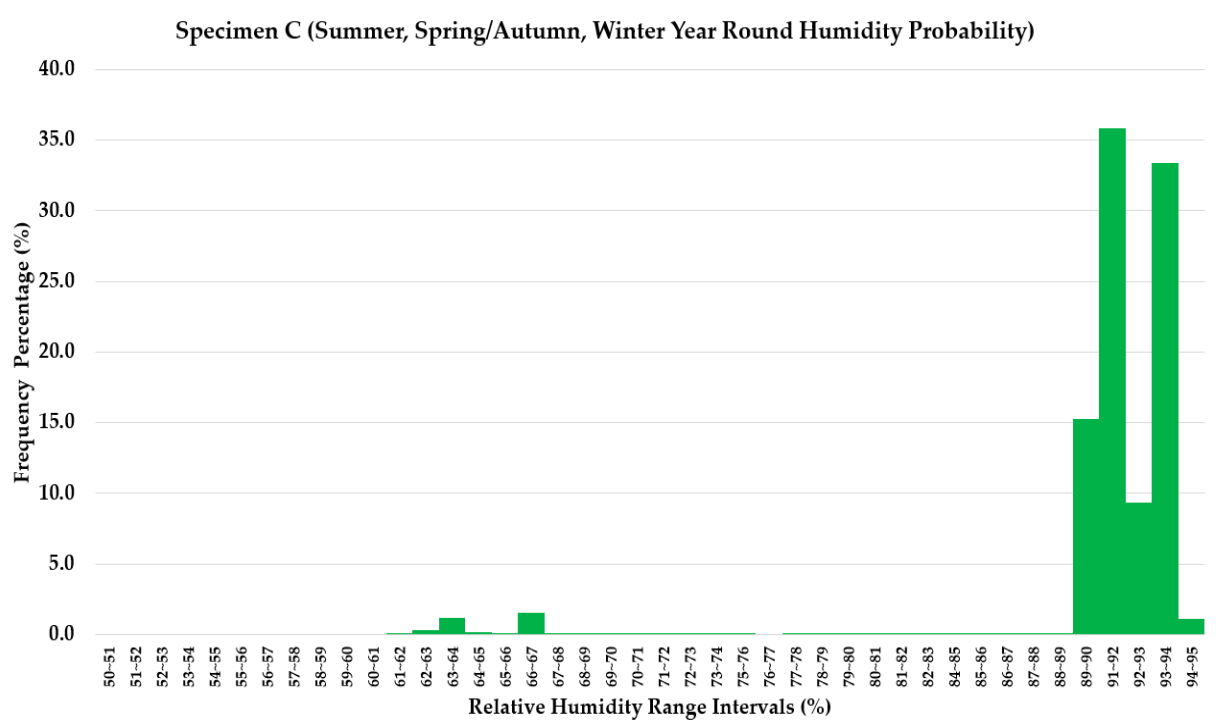

(c)

Figure 11. Probability density of RH measurement of three types of specimen throughout the three seasonal changes (year round), (a) Specimen A results (b) Specimen B results, and (c) Specimen C results.

With respect the entire evaluation regime proposed in this study, the following Table 6 provides the summary of the performance evaluation results from the analysis process discussed in the previous sections.

The results of this evaluation method demonstration cements the reasoning that waterproofing materials have a significant influence on humidity, as they are the frontier for providing ingress or permeation of water in the concrete substrate. Based on the above observations in the separate seasonal temperature conditioning, it can be seen that Specimen A (urethane coating material) has the highest RH humidity control performance throughout the year, whereas Specimens B and C are not able to meet the standard criteria in comparison. This simplified representation of the respective waterproofing material type and installation methods allows a clearer comparison in terms of the $\mathrm{RH}$ control performance when installed in a concrete structure. 
Table 6. Comprehensive results.

\begin{tabular}{|c|c|c|c|c|c|c|c|c|c|c|c|c|c|c|c|}
\hline \multirow{3}{*}{$\begin{array}{c}\text { Temp. } \\
\text { Condition } \\
\left({ }^{\circ} \mathrm{C}\right)\end{array}$} & \multicolumn{15}{|c|}{ Evaluation Results } \\
\hline & \multicolumn{5}{|c|}{ Specimen A } & \multicolumn{5}{|c|}{ Specimen B } & \multicolumn{5}{|c|}{ Specimen C } \\
\hline & $\begin{array}{l}\text { Avg. } \\
(\%)\end{array}$ & $\begin{array}{c}\text { Intercept } \\
(\%)\end{array}$ & $\begin{array}{c}\operatorname{Max} \\
(\%)\end{array}$ & Slope & $\begin{array}{c}\text { Range } \\
(\%)\end{array}$ & $\begin{array}{l}\text { Avg. } \\
(\%)\end{array}$ & $\begin{array}{c}\text { Intercept } \\
(\%)\end{array}$ & $\begin{array}{c}\operatorname{Max} \\
(\%)\end{array}$ & Slope & $\begin{array}{c}\text { Range } \\
(\%)\end{array}$ & $\begin{array}{l}\text { Avg. } \\
(\%)\end{array}$ & $\begin{array}{c}\text { Intercept } \\
(\%)\end{array}$ & $\begin{array}{c}\operatorname{Max} \\
(\%)\end{array}$ & Slope & $\begin{array}{c}\text { Range } \\
(\%)\end{array}$ \\
\hline $\begin{array}{l}\text { Winter } \\
\left(4^{\circ} \mathrm{C}\right)\end{array}$ & 51.78 & 52.86 & 54.42 & $-2.7 \times 10^{-3}$ & \multirow{3}{*}{$50 \sim 70$} & 73.42 & 64.25 & 77.79 & $-2.32 \times 10^{-2}$ & \multirow{3}{*}{$52 \sim 90$} & 88.14 & 84.31 & 90.25 & $9.7 \times 10^{-3}$ & \multirow{3}{*}{$61 \sim 95$} \\
\hline $\begin{array}{l}\text { Spring/Autumn } \\
\left(20^{\circ} \mathrm{C}\right)\end{array}$ & 57.10 & 58.27 & 58.31 & $-3 \times 10^{-3}$ & & 75.87 & 66.08 & 81.64 & $2.48 \times 10^{-2}$ & & 90.69 & 86.27 & 92.41 & $1.12 \times 10^{-3}$ & \\
\hline $\begin{array}{l}\text { Summer } \\
\left(40^{\circ} \mathrm{C}\right)\end{array}$ & 65.47 & 52.86 & 69.16 & $-7.2 \times 10^{-3}$ & & 79.06 & 69.86 & 87.85 & $2.33 \times 10^{-2}$ & & 88.38 & 89.08 & 93.43 & $-1.8 \times 10^{-3}$ & \\
\hline
\end{tabular}




\section{Conclusions}

This study proposed a new evaluation method as well as confirming:

(1) that waterproofing material (type and existence of) impacts humidity in the negative side of the concrete structure across different seasonal conditions;

(2) an evaluation of the average, intercept and maximum $\mathrm{RH}$, slope, and the $\mathrm{RH}$ variance range can be used to compare the different waterproofing methods and materials' humidity control performance

(3) the study results provide an insight on how easy future humidity control would be given a waterproofing material.

While this evaluation method requires revisions to better simulate the below-grade structure environment, it serves as a basis for selecting optimal waterproofing materials. Future research will include criteria for optimal humidity conditions for indoor comfort, prevention of radon ingress and mold growth, and a cost efficiency analysis based on electricity usage. Future evaluation using this method will include assessment and comparison results of different types of materials commonly used in underground concrete structures including asphalt or synthetic polymer sheet.

Author Contributions: S.-k.O., K.-w.A. and K.-h.O. conceived and designed the experiments; K.-w.A. and K.-h.O. performed the experiments; S.-k.O., K.-w.A. and K.-h.O. analyzed the data; K.-w.A and K.-h.O. wrote the paper. All authors have read and agreed to the published version of the manuscript.

Acknowledgments: This research was supported by a grant(20RERP-B082204-07) from Residential Environment Research Program funded by Ministry of Land, Infrastructure and Transport of Korean government.

Conflicts of Interest: The authors declare no conflict of interest. The founding sponsors had no role in the design of the study; in the collection, analyses, or interpretation of data; in the writing of the manuscript; or in the decision to publish the results.

\section{Abbreviations}

$\begin{array}{ll}\text { ASTM } & \text { American Standards for Testing and Materials } \\ \text { BS EN } & \text { British Standard European } \\ \text { GB } & \text { Guobiao } \\ \text { KS } & \text { Korean Industrial Standards } \\ \text { LH } & \text { KOREA LAND \& HOUSING CORPORATION } \\ \text { RH } & \text { Relative Humidity }\end{array}$

\section{References}

1. An, K.W.; Lee, Y.S.; Lee, J.H.; Song, J.Y.; Oh, S.K. Humidity Change Rate Analysis for Various Waterproofing Method in Underground Structures During Winter Season. J. Korea Inst. Struct. Maint. Insp. 2016, 20, 118-125.

2. Chang, S.M.; Oh, S.K.; Seo, D.S.; Choi, S.M. Characteristics of Humidity-Temperature Changing in the Below-Grade Concrete Structure by Applying Waterproofing Materials on the Exterior Wall. Adv. Build. Technol. Constr. Mater. 2015, 2015. [CrossRef]

3. Ismail, M.; Egba, E.I. Effects of climate and corrosion on concrete behavior. AIP Conf. Proc. 2017, $1903,020027$. [CrossRef]

4. IAQ. Moisture Control Guidance for Building Design, Construction and Maintenance, Printable Version; Createspace Independent Publishing Platform: Scotts Valley, CA, USA, 2014.

5. Zhu, F.Z.; Ma, Z.M.; Zhao, T.J. Influence of Freeze-Thaw Damage on the Steel Corrosion and Bond-Slip Behavior in the Reinforced Concrete. Adv. Build. Technol. Constr. Mater. 2016, 2016. [CrossRef]

6. An, K.W.; Kim, D.B.; Huh, N.H.; Park, J.S.; Oh, S.K. A Study on Humidity Difference between Particular Temperature Environment and Waterproofing Methods to Underground Structures; Korea Scholar: Seoul, Korea, 2014; pp. 779-782. 
7. Francis, R. Humidity and Dew Point: Their Effect on Corrosion and Coatings. In Proceedings of the ACA Annual Conference Proceedings, Victoria, Australia, 13 January 2020; Available online: https://www. academia.edu/17021842/Humidity_and_Dew_Point_Their_Effect_on_Corrosion_and_Coatings (accessed on 1 February 2020).

8. Yang, J.; Peng, G.-F.; Shui, G.; Zhang, G. Mechanical Properties and Anti-Spalling Behavior of Ultra-High Performance Concrete with Recycled and Industrial Steel Fibers. Materials 2019, 12, 783. [CrossRef] [PubMed]

9. Seitllari, A.; Naser, M.Z. Leveraging artificial intelligence to assess explosive spalling in fire-exposed RC columns. Comput. Concr. 2019, 24, 271-282. [CrossRef]

10. Shah, A.H.; Sharma, U.K. Fire resistance and spalling performance of confined concrete columns. Constr. Build. Mater. 2017, 156, 161-174. [CrossRef]

11. Jansson, R. Fire Spalling of Concrete: Theoretical and Experiment Studies. Ph.D. Thesis, KTH Royal Institute of Technology, Stockholm, Sweden, 2013.

12. Public Works Department of Malaysia. Guidelines on the Prevention of Mould Growth in Buildings; Public Works Department of Malaysia: Kuala Lumpur, Malaysia, 2009.

13. Zuzana, R.; Ryparová, P. The Dependence of Mold on the Relative Humidity in Different Types of Materials. In Key Engineering Materials; Trans Tech Publications, Ltd.: Zürich, Switzerland, 2017; Volume 731, pp. 98-102. [CrossRef]

14. Jareemit, D.; Shu, S.; Heidarinejad, M.; Kim, Y.S.; Liu, J.; Alhafi, Z.A.; Srebric, J. Evaluation of Indoor Mold Growth Relative to Indoor Humidity Using a Multi-zone Modeling. 2013. Available online: https://www. researchgate.net/profile/Mohammad_Heidarinejad/publication/266375006_Evaluation_of_Indoor_Mold_ Growth_Relative_to_Indoor_Humidity_Using_a_Multi-zone_Modeling/links/5432dd140cf22395f29d035c/ Evaluation-of-Indoor-Mold-Growth-Relative-to-Indoor-Humidity-Using-a-Multi-zone-Modeling.pdf (accessed on 17 December 2019).

15. Pernilla, J.; Svensson, T.; Annika, E.-T. Critical moisture conditions for mould growth on building materials. Build. Environ. 2013, 62, 201-209. [CrossRef]

16. American Society of Heating, Refrigerating, and Air-Conditioning Engineers, Inc. Thermal Environmental Conditions for Human Occupancy; American Society of Heating, Refrigerating, and Air-Conditioning Engineers: Atlanta, GA, USA, 2010.

17. ASHRAE. Moisture Control Guidance for Building Design, Construction and Maintenance; ASHRAE: Atlanta, GA, USA, 2016; ISBN 9781939200426.

18. Groves-Kirkby, C.J.; Crockett, R.; Denman, A.R.; Phillips, P.S. Climatic and seasonal influences on radon time series in an environment of low anthropogenic activity. In Proceedings of the 13th International Congress of the International Radiation Protection Association (IRPA13), Glasgow, UK, 13-18 May 2012; Available online: http://www.irpa.net/members/P10.74FP.pdf (accessed on 13 January 2020).

19. U.S. Department of the Interior/U.S. Geological Survey. The Geology of Radon; U.S. Government Printing Office: Washington, DC, USA, 1992.

20. Fernandez-Cortes, A.; Benavente, D.; Cuezva, S.; Cañaveras, J.C.; Alvarez-Gallego, M.; Garcia-Anton, E.; Soler, V.; Sanchez-Moral, M. Effect of Water Vapour Condensation on the Radon Content in Subsurface Air in a Hypogeal Inactive-Volcanic Environment in Galdar Cave, Spain; Atmospheric Environment; Elsevier: Amsterdam, The Netherlands, 2013; Volume 75, pp. 15-23.

21. Turk, B.; Hughes, J.; Center, S.R. Exploratory Study of Basement Moisture During Operation of ASD Radon Control Systems; US Environmental Protection Agency Indoor Environments Division: Washington, DC, USA, 2008.

22. BSI. BS 8102:2009 Code of Practice for Protection of Below Ground Structures against Water from the Ground; BSI: London, UK, 2009.

23. ASTM D7832/D7832M-14. Standard Guide for Performance Attributes of Waterproofing Membranes Applied to Below-Grade Walls/Vertical Surfaces (Enclosing Interior Spaces); ASTM International: West Conshohocken, PA, USA, 2014.

24. The 3rd Research Institute of Engineering Corps-General Staff of PLA. Technical Code for Waterproofing of Underground Works (GB 50108-2008), Approved by Ministry of Housing and Urban-Rural Development of China; The 3rd Research Institute of Engineering Corps-General Staff of PLA: Beijing, China, 2008.

25. Song, J.Y.; Oh, K.H.; Kim, B.I.; Oh, S.K. Performance Evaluation of Waterproofing Membrane Systems Subject to the Concrete Joint Load Behavior of Below-Grade Concrete Structures. Appl. Sci. 2017, 7, 1147. [CrossRef] 
26. Jang, S.M.; Choi, S.M.; Lee, J.H.; An, K.W.; Oh, S.K. A Study on the Characteristics of Temperature-Humidity by the Location of Waterproofing Layer with the Concrete Wall as the Center in the Basement; Korea Concrete Institute: Korea, Seoul, 2013; Volume 10, pp. 31-32.

27. Deckard, C.; Hagerty, P.D. Rethinking Waterproofing for Subsurface Structures. In Forensic Engineering 2009: Pathology of the Built Environment, 1st ed.; Chen, S.-E., de Leon, A.D., Dolhon, A.M., Drerup, M.J., Parfitt, M.K., Eds.; American Society of Civil Engineers (ASCE): Washington, DC, USA, 2009; pp. 298-307.

28. Oh, S.K.; Shim, J.S. Maintenance for Leakage due to Cracking in Concrete Structures-Guidelines for Repair of Water-Leakage Cracks in Concrete Structures. J. Korea Concr. Inst. 2011, 23, 47-52.

29. An, K.W.; Kang, H.J.; Oh, K.H.; Kim, S.Y.; Oh, S.K. A Study on the Environmental Degradation Factors and the Required Performance of the Waterproofing Materials Applied to Underground Structures in Residential Apartment Buildings. Korea Inst. Build. Constr. 2017, 17, 213-214.

30. An, K.W.; Kang, H.J.; Kim, S.Y.; Oh, S.K. An analysis of the Factors Influencing Leakage of Below-Grade Concrete Structures in Residential Buildings-Survey Centered Data. Korea Inst. Build. Constr. 2017, 17, 73-74.

31. Korea Land \& Housing Corporation. Establishment of Measures to Improve Quality of House Waterproofing Methods for Zero Defects in Quality Management; Public Housing Project Office: Gyeongnam, Korea, 2017; p. 3.

32. Korea Meteorological Administration. 2012 Monthly Weather Report; 2012. Available online: http://www.kma. go.kr/eng/weather/forecast/currentkorea.jsp (accessed on 16 December 2019).

(C) 2020 by the authors. Licensee MDPI, Basel, Switzerland. This article is an open access article distributed under the terms and conditions of the Creative Commons Attribution (CC BY) license (http://creativecommons.org/licenses/by/4.0/). 